\title{
THE USE OF TQM AS A MODEL TO IMPROVE UNIVERSITY PERFORMANCE IN INDONESIA
}

\author{
Burhanuddin; Achmad Supriyanto \\ Universitas Negeri Malang \\ Email: burhanuddin.fip@um.ac.id
}

\begin{abstract}
The purpose of this study is to assess higher education performance in Indonesia, and how TQM is used as a model to promote this sector. The investigation was conducted employing a meta-analysis technique. Literatures and findings from some studies were reviewed to explore the performance indicators and how these were improved employing this model. Results identified unsatisfied universities performance and its development still moved slowly. Insufficient governance was found as one of factors influencing this condition. Future studies are needed to discover broader insights about appropriate models in improving the performance.
\end{abstract}

Keywords: university, management, TQM, improvement, teaching and learning

\section{INTRODUCTION}

The management performance is perceived as a strategic issue for higher education institutions in Indonesia. Reports on the development of this sector indicate that the improvement of universities in Asia specifically Indonesia move slowly (UNESCO, 2014). Insufficient governance was found as one of the factors to influence universities performance in many countries (Bryman, 2007). While global competitions challenge universities in this region, the improvement of higher education management is vital to ensure the universities survive in this global context (Bryman, 2007; Marginson, 2006; Marginson \& Sawir, 2006).

Higher education system (HES) across countries has to be able to deal with new ventures enforced by educational reformations (Marginson, 2006; Marginson \& Sawir, 2006). To participate successfully in the competitive environment, universities as a part of the system need to have capacities to provide effective services to students, stakeholders, and other community members. Its efficacy, however, is constrained by a lot of factors including individual characteristics, social culture, and unpredictable changes of the global environment (ADB, 2011). This is experienced by most universities in the world, and they cannot be excluded from this challenge. Hence, executives, then have to examine how these factors influence, and what solutions required in enhancing higher education performance.

With respect to this issue, this article proposes TQM as an alternative technique to promote universities performance. How TQM is modeled as an approach to improve university performance is sought and discussed in this paper.

Decision makers and management specialists in the area of organization development have investigated strategies to deal with the changing demands. TQM is viewed as one of the strategies that has been widely developed as a model of organizational improvement that can be applied in various organizations both private and government as well as universities, schools, and business projects (Sadikoglu \& Olcay, 2014; Sila, 2007). This approach focuses on the quality improvement program for the components of an organizational system within university structure. In organization studies, TQM is also known as one of the contemporary approaches that have positive impacts on efforts to maintaining organizations and their resources (Kanji, Malek, \& Tambi, 1999 ; Lo, Wiengarten, Humphreys, Yeung, \& Cheng, 2013), so that the university is able to sustain its capacity in carrying out the missions of organization (Goetsch \& Davis, 2002). Although some experts criticize the compatibility of TQM methodological dimensions to be implemented in many universities (Houston, 2007), some authors assumed basic principles of quality model can be 
used as a framework for the quality improvement projects at all levels (Sila, 2007). It has significant impacts on the increased performance enterprises (Lo et al., 2013). Research found the ability of TQM model in empowering individuals and building team work (Hur, 2009; Sila, 2007).

The core values of education at university level are placed on the extent of how the human resources empowerment, and the steps of education implementation are synergic with the development efforts for students' individual learning capacity (Bryman, 2007; Harris \& Spillane, 2008; Jones, Lefoe, Harvey, \& Ryland, 2012).

Defining TQM, it is necessary to understand the meaning of "quality". In general, this approach is often interpreted as an attempt to please the customers (customers) to meet the demands and their desires (McKee, Kemp, \& Spence, 2013). This concept may include various forms such as service quality in terms of appearance, state of the product, availability, delivery, reliability, maintenance, and proper price. While TQM is defined as: "An organizational strategy of commitment to improving customer satisfaction by developing techniques to carefully manage output quality" (Greenberg and Baron, 1995). It is simply defined as a strategy to build the organization's commitment to improve customer satisfaction by managing the quality of services for the customer.

University executives, faculty members, and administrative staff have to be able to manage the operations of universities inducing total quality values in all steps. This strategy needs to be adopted to ensure customers consisting of stake holders and education providers satisfied. The success of quality management requires knowledge and understanding on this TQM technique as a system work (Kanji et al., 1999 ).

Total Quality is one of the organizational approach, developed based on the view (philosophy of) with the basic principles of continuous improvement to respond the various forms of needs and wishes of the customer (McKee et al., 2013). Specifically, organizations implementing TQM approach has a view of life as follows: focuses specifically on customers, attention efforts on continuous improvement, focus on the quality process, improving the quality of all aspects of the organization's work, performance measure- ment and quality accurately, and empowerment of the members of the organization (Burhanuddin, 2016).

Quality model has concrete goals, and known by all members so that all people will contribute totally to the process of quality, the obsession to the quality of any services provided, and produce the final product satisfying work both from the viewpoint of customers and for the benefit of the development of the organization in the long term (Burhanuddin, 2016). Empowerment functions are carried out for all individuals to support the improvement programs, development of quality jobs as which are summarized in Figure 1 (Hur, 2009; Randolph \& Blanchard, 2007). The new organizational culture is built and developed in such a way to guarantee the implementation of the quality improvement program as an on-going process (Hur, 2009). If the existing organizational culture does not match with the behavioral characteristics of the changes of quality change, then the quality improvement efforts do not work properly (Houston, 2007; Sadikoglu \& Olcay, 2014). To support the continuity of quality improvement program, curriculum adaptation, curriculum adjustment has to be conducted proportionally.

\section{METHOD}

This study uses a simple meta-analysis that develops and discusses research findings based on multiple scientific results of studies. Basic assumption of this technique is that there is a common evidence retrieved from several studies where errors in the respective studies are estimated. To derive pooled estimates which are closer to unknown common truth, certain statistics approaches were used. Metaanalysis is able to compare results from some studies, identify patterns of findings among the studies, differences, sources of those results, and relationships that come up from the multiple studies (Oxford, 2017). The subjects included in this study were studies from articles, book chapters, government regulations, and other related published works. The major requirements for inclusion are quantitative data some qualitative studies reported in published works including journals, books, proceedings, or other scientific results. 


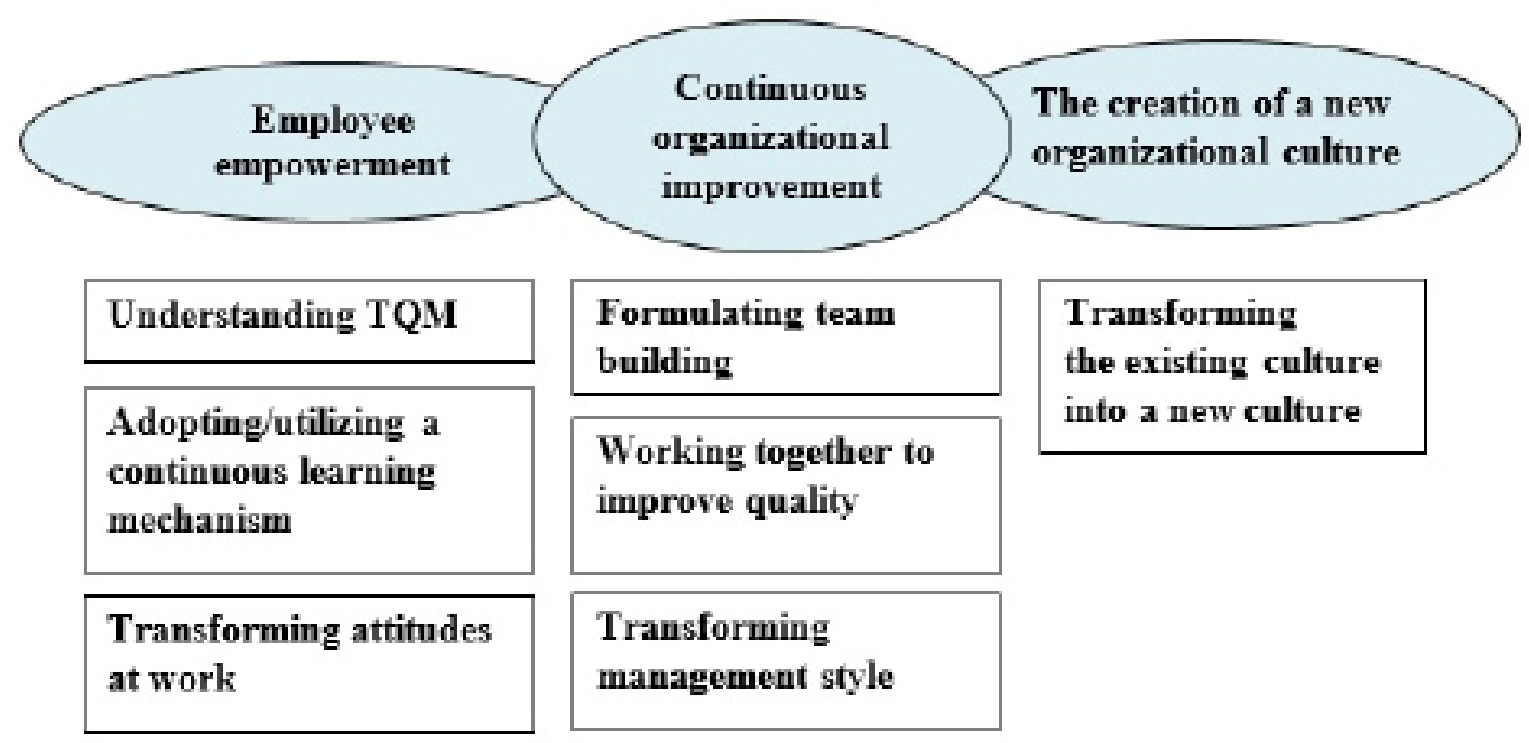

Figure 1 TQM objectives at university organization structure, Source: Hur, 2009

\section{RESULT}

Reports from global examination on higher education development across countries indicate that universities in Asian countries experienced lower performance level compared to other universities in Europe, Australia, and America. The performance of universities in the case of Indonesia, none of universities has been ranked in the best ten, even the top 100 (Times Higher Education, 2016; UNESCO, 2014). Although the expansion of universities increased in number significantly, however their quality development moves slowly (UNESCO, 2014; Welch, 2007). Competitive efforts in the development of areas such as research product, teaching and learning performance, student capacity, academic staff or faculty performance, and innovations technology products or university inventions - still below the performance of other Asian countries (UNESCO, 2014). Such a condition attract the author to propose an alternative model of university management in enhancing organizational performance, in particular, as limited in this article the improvement of teaching and learning (TL) services through employing TQM model.

Based on literature reviews and research studies, the implementation of total quality management in improving the management performance for Indonesian universities particularly teaching and learning system and other services can adopt the following basic procedure. This be- gins with commitment of university leaders who work the best to meet expectations of students, parent, community members, government, industry, graduates' employers, businessmen, and other stakeholders. All the components of managerial system must be developed valuing the principles of total quality management approach. The operations of components in university services have to be well integrated and continuously improved in responding to the current conditions faced by universities.

The system of quality insurance of university services in particular teaching learning (TL) activities is established and executed to guarantee all students (as the clients) have quality TL and other services within the university organization structures. These quality expectations can be measured by examining the achievements concerning the specifications of process and outputs of the university organizations. Standards of both process and output, then, have to be formulated systematically and prepared at each level of activities. The selection of the standards are strengthened through issuing university policies in terms of vision, mission, goals, and targets.

Based on national standards of higher education issued by Ministry of Education (2014), the quality improvement of higher education management (HEM) in Indonesia is oriented towards the quality fulfillment of management components: 
(1) content standard, (2) process, (3) graduates competencies, (4) educators and educational staff members, (5) infrastructure, (6) management, (7) finance, and (8) educational evaluation. Additional standards are research studies, community extension services, cooperation, information system, and academic climate. These standards are used as a direction and minimum requirement that have to be fulfilled by universities in accomplishing the vision and missions.

Ideally, standard components are developed hierarchically and systematically developed, firstly at the university level, faculty, department, and study programs. Such a procedure is necessary to provide element values of TQM which are able to get the acceptance of all organization members, and understood by individuals being involved in the management systems. This helps leaders and managers easily control the progress of quality management in the process and output of the teaching learning or other university services provided to all clients. To illustrate in detail how this TQM model is applied in improving the quality of teaching learning as a part of university services, several steps of the model are summarized in Figure 2.

TQM components interact with each other in producing graduates who qualified through a developed learning process. The program of the teaching learning quality begins with the recruitment of students as raw inputs and lecturers as instrumental inputs. Teaching learning activities are monitored every day to determine the effectiveness of the activities that have been planned. Feedback information is collected in order to assess the success of learning activities. Lecturers, then, provide corrective measures continuously, by applying new approaches and innovative in order to build a better learning model. This interaction result is then measured to evaluate the extent to which the objectives have been achieved in the learning process. In the end, the quality improvement program is expected to be able to provide high quality graduates that can meet the quality standards and the demands of the labor market.

The success of teaching learning activities in universities always becomes a common target of education oriented to the total quality approach. Lecturers who have a commitment to apply TQM model in designing and implementing their teaching learning programs can begin the model through cyclic steps as illustrated in Figure 3.

At the first step, lecturers prepare lesson plans and design effective teaching strategies. They systematically plan what sorts of activities to be performed in improving the quality of teaching and learning through a total approach. Lecturers and administrative staff try to answer guiding questions: what, why, when, where, and how? They have responsibilities to make the teaching plans to be implemented in each classroom. Several components of the teaching

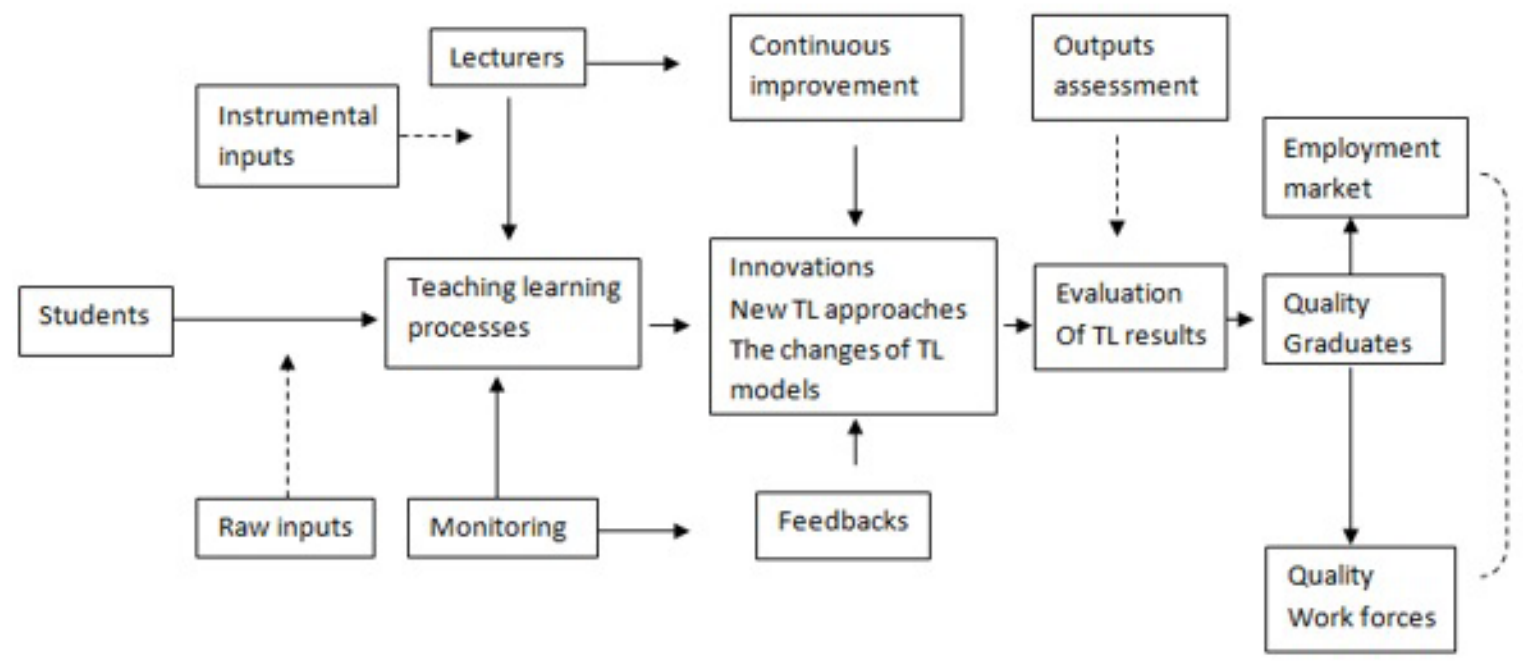

Figure 2 The improvement of teaching and learning using TQM approach in a university 


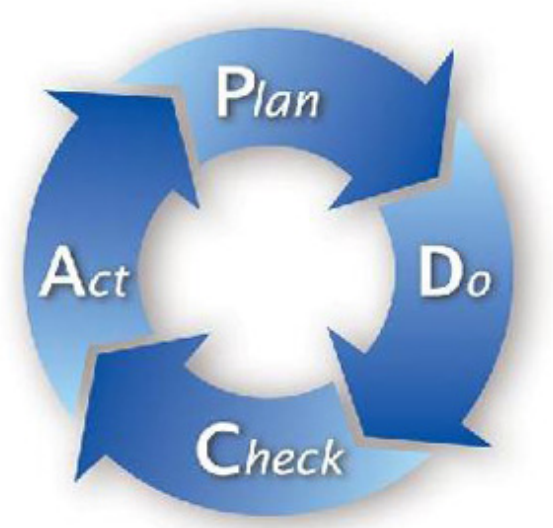

Figure 3 TQM cycle in improving teaching and learning for students

learning activities include: learning outcome, competencies, material or subjects to be taught, and strategies (method, learning activities, evaluation system). Universities and the study programs may have different format of these components. All the preparation steps are designed to satisfy students as the clients in teaching and learning process. Such satisfaction is related to students' learning achievements, subjects to be taught, methods, learning environment, and the performance of lecturers' performance in the classroom or during the contacts with the learners. Indonesian government issued the Rule Number $19 / 2005$ on the national standard of education. The standard include: the content, process, graduate competencies, and evaluation. These standard elements can be applied as indicators in performing teaching learning activities and their performance measurement. How the designed learning activities to be implemented can be measured using these standards as indicators. The fulfillment of these elements in teaching learning process automatically satisfy students as the clients in the system. Followed by implementing what have been planned in attaining the target of quality education programs in the campus. All the elements that have been designed in the lesson plans for example, have to be considered as the pointers to carry out teaching and learning activities.

To check and monitor the progress of teaching learning activities are necessary to ensure the quality targets are fulfilled. Lecturers and students collect information on the achievement of learning objectives, level of student satisfaction upon the subjects taught, method, environment, facility, and interaction. Based on these questions, they both can improve the condition of teaching learning and the models of how learning strategies implemented effectively in the future.

The last stage is to follow up the progress or the conditions found during the process of teaching and learning. Students and lecturer employ corrective and refinement actions to the elements that have not been fulfilled satisfactorily. They may develop the new lesson plans, method changes, regroup the students, the changes of communication and interaction models, classroom format changes, and evaluation procedure is resumed.

The implementation of TQM model in this context can also be explained through the following diagram as shown in Figure 4.

To support its success, the implementation of TQM must be synergic with every system component in particular the programs and activities designed in the university organizations or units. Every strategy has to pursue totally the achievement of high satisfaction for any clients. The fishbone in Figure 5 show how each component dependently synergize to each other.

Finally, to measure the effectiveness in achieving its target, the success of TQM is based on the main indicators. Some of these include: quality of graduates, services, staff quality performance, evaluate, process or work mechanism, and quality of university environment. University leaders may determine the level of targets quality through answering questions that relate to the specified indicators as listed in the following matrix (Figure 6).

How those indicators are fulfilled, will guide managers and their members to assess the extent of TQM targets achieved in university organizations.

\section{DISCUSSION}

The use of TQM as a model improving university performance is relevant with many experiences as investigated in the private and public enterprises, and many university organizations (Sadikoglu \& Olcay, 2014; Sila, 2007). Although the model has been employed for many years beyond educational settings, however, this has been acknowledged by most university leaders as one 
- Teaching learning approaches

- Organizational culture

- Managerial and leadership

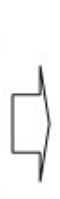

Optimization of quality improvement program to enhance the competitiveness capacity of the university and excellence graduates
- Quality graduates

- Services

- Human resources

- Process

- School environment

Figure 4 TQM implementation

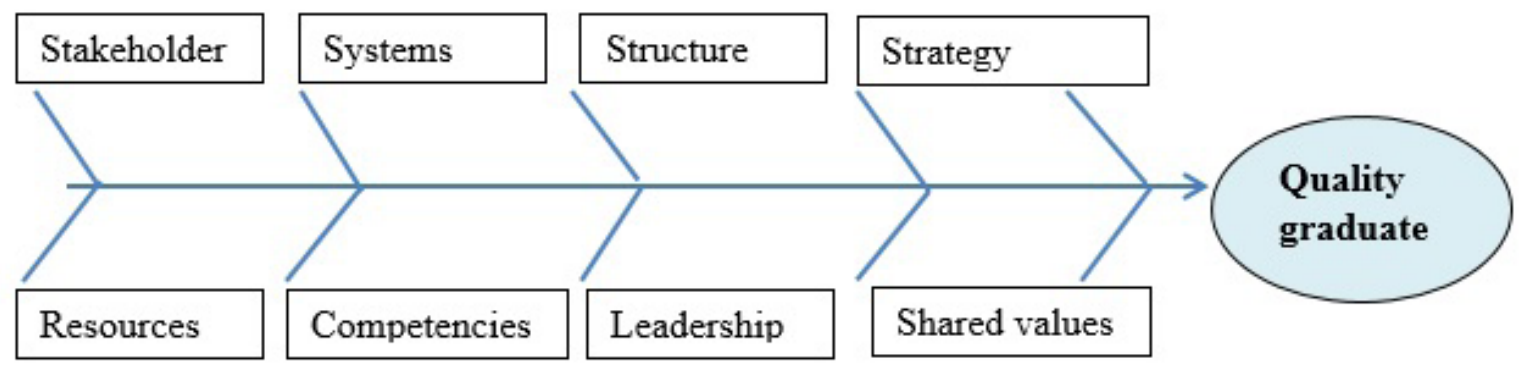

Figure 5. The synergy of system components

\begin{tabular}{|c|c|c|c|c|}
\hline $\begin{array}{c}\text { Graduate } \\
\text { Quality }\end{array}$ & Services & $\begin{array}{c}\text { Human } \\
\text { resources }\end{array}$ & Process & Environment \\
\hline$?$ & $?$ & $?$ & $?$ & $?$ \\
\hline
\end{tabular}

Figure 6 Indicators of TQM implementation

of the innovative approaches to enhancing the performance of higher educational management for the units of hierarchical university structures (Houston, 2007; Sadikoglu \& Olcay, 2014). Evidences from many research studies indicated significant improvements in terms of the increased productivity of employees and the overall changes to advancing public services provided by organization members to the customers (Kanji et al., 1999 ; Lo et al., 2013). Thus, academic and administrative services provided in universities can be improved through using this model. Lecturers are advised to apply the model in increasing the level of satisfaction for their students as client. Employees can design their jobs adopting TQM as a model to ensure customers within the university environment to be satisfied with any services they may get from the employees. These initiatives are regarded as excellent ways to get more benefit from organizational efforts in achieving a higher level performance for their university as an institution that provide services to the public (Houston, 2007; Jones et al., 2012). Hence, both ideographic and nomothetic needs can be fulfilled in managing the higher education system.

\section{CONCLUSION}

The quality of teaching and learning involving students and lecturers can be improved effectively when all elements of teaching learning system are framed in referring to the values and principles of TQM model. Executives, lecturers, and other members need to design certain approaches and techniques to implement university services specifically learning activities for students. Programs are properly prepared, implemented, monitored, and evaluated continuously. Feedbacks are considered in responding to the demands of the challenging environment within the global context. This stage is vital for providing students with quality education. Universities, then, are able to produce graduates who obtain 
higher independent capacities for living successfully in the future.

\section{REFERENCES}

ADB. 2011. Higher education across Asia: an overview of issues and strategies. Manila: Asian Development Bank (ADB)

Bryman, A. 2007. Effective leadership in higher education: A literature review. Studies in Higher Education, 32(6), 693-710. doi: 10.1080/03075070701685114

Burhanuddin. 2016. Perilaku organisasi dalam manajemen dan kepemimpinan (Organizational behaviour in management and leadership) Malang: Penerbit \& Percetakan UM.

Goetsch, D. L., \& Davis, S. B. 2002. Quality management: An introduction of total quality management for production, processing, and services (4th ed.). Indianapolis: Prentice Hall.

Harris, A., \& Spillane, J. 2008. Distributed leadership through the looking glass. Management in education, 22(1), 31-34.

Houston, D. 2007. TQM and higher education: A critical systems perspective on fitness for purpose. Quality in Higher Education, 13(1), 4-17.

Hur, M. H. 2009. The influence of total quality management practices on the transformation of how organisations work. Total Quality Management, 20(8), 847-861.

Jones, S., Lefoe, G., Harvey, M., \& Ryland, K. 2012. Distributed leadership: A collaborative framework for academics, executives and professionals in higher education. Journal of Higher Education Policy and Management, 34(1), 67-78.

Kanji, G. K., Malek, A., \& Tambi, B. A. 1999 . Total quality management in UK higher education institutions. Total Quality Management, 10(1).

Lo, C. K. Y., Wiengarten, F., Humphreys, P., Yeung, A. C. L., \& Cheng, T. C. E. 2013. The impact of contextual factors on the efficacy of ISO 9000 adoption. Journal of Operations Management, 31(5), 229-235.
Marginson, S. 2006. Dynamics of national and global competition in higher education. Higher Education, 52, 1-39. doi: 10.1007/ s10734-004-7649-x

Marginson, S., \& Sawir, E. 2006. University leaders' strategies in the global environment: A comparative study of Universitas Indonesia and the Australian National University. Higher Education, 52, 343-373. doi: 10.1007/s10734-004-5591-6

McKee, A., Kemp, T., \& Spence, G. 2013. Management: a focus on leaders. Frenchs Forest, N.S.W.: Pearson.

The Rule of Minstry of Education and Culture Indonesia Number 49 the Year 2014 on National Standard of Higher Education (2014).

Oxford, U. o. 2017. What is a meta-analysis? Centre for evidence based intervention (CEBI) https://www.cebi.ox.ac.uk/for-practitioners/what-is-good-evidence/what-is-ameta-analysis.html.

Randolph, A., \& Blanchard, K. (2007). Empowerment is the key. In T. Moore (Ed.), Leading at a higher level: Blanchard on leadership and creating high performing organizations. Upper Saddle River, New Jersey: Pearson Prentice Hall.

Sadikoglu, E., \& Olcay, H. (2014). The effects of total quality management practices on performance and the reasons of and the barriers to TQM practices in Turkey. Advances in Decision Sciences, 2014.

Sila, I. 2007. Examining the effects of contextual factors on TQM and performance through the lens of organizational theories: An empirical study. Journal of Operations Management, 25(1), 83-109.

Times Higher Education. (2016). Worlduniversity-rankings.

UNESCO. 2014. Higher education in Asia: Expanding Out, Expanding Up. Montreal: UNESCO Institute for Statistics.

Welch, A. R. (2007). Blurred Vision?: Public and private higher education in Indonesia. Higher Education, 54(5), 665-687. doi: 10.1007/s10734-006-9017-5 